Canadian Journal of Fisheries and Aquatic Sciences

Canadian

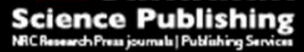
Journal canadien des sciences halieutiques et aquatiques

\title{
Incorporation of optimal environmental signals in the prediction of fish recruitment using random forest algorithms
}

\begin{tabular}{|r|l|}
\hline Journal: & Canadian Journal of Fisheries and Aquatic Sciences \\
\hline Manuscript ID & cjfas-2017-0554.R1 \\
\hline Manuscript Type: & Article \\
\hline Date Submitted by the Author: & 19-Mar-2018 \\
\hline $\begin{array}{r}\text { Complete List of Authors: } \\
\text { Is the invited manuscript for } \\
\text { consideration in a Special } \\
\text { Issue? : }\end{array}$ & N/A \\
\hline Keyword: & herring, sprat, climate, machine learning, data mining \\
\hline & \\
\hline
\end{tabular}

\section{SCHOLARONE" \\ Manuscripts}


1 Incorporation of optimal environmental signals in the prediction of fish

2 recruitment using random forest algorithms

3 Szymon Smoliński

Department of Fisheries Resources, National Marine Fisheries Research Institute, Kołłataja 1,

$5 \quad$ 81-332 Gdynia, Poland

6 tel.: +48 587-356-193, e-mail: ssmolinski@mir.gdynia.pl

\section{Abstract}

8 The drivers of recruitment of selected Baltic sprat (Sprattus sprattus) and herring (Clupea

9 harengus) stocks were investigated. Data on the interaction dynamics among fish species, the

10 biological characteristics of the stocks, the biomass of the main predators and the hydroclimatic

11 environmental factors (Baltic Sea Index (BSI) and sea surface temperature (SST)) were used in

12 the analysis. The combination of random forest (Boruta algorithm) and "sliding window"

13 approaches was tested on the simulated data and then used for the selection of relevant predictors

14 and the optimal time window for real environmental variables. SST had a significant positive

15 effect on the recruitment processes. Moreover, contrasting effects were observed in the mean

16 BSI from two different time windows. The same environmental variable generated contrasting

17 short-term and long-term effects on fish recruitment. This paper highlights the potential benefits

18 of random forest and data mining applications for the incorporation of environmental factors in

19 the assessment of stocks. The proposed analytical approach may be valuable for the

20 investigations of complex environmental impacts in a broad range of ecological studies.

\section{$21 \quad$ Keywords}

22 Baltic Sea, herring, sprat, climate, machine learning, data mining, sliding window 


\section{INTRODUCTION}

25 Fish population dynamics depend strongly on recruitment processes (Cushing 1996), which were

26 widely identified in 1980 s as the crucial elements to be considered for effective management

27 (Checkley et al. 2009). The recent availability of open-source environmental data provides an

28 opportunity to test a variety of predictors that may have an influential role in stock recruitment.

29 However, traditional statistical tests are often not flexible enough to analyze such complex data

30 (Elith et al. 2008). Relationships between the number of recruits and environmental drivers are

31 frequently nonlinear (Drinkwater 2005). Moreover, various interactions between drivers may

32 occur in these ecological systems (Dreyfus-León and Chen 2007). To handle these challenges,

33 machine learning (ML) techniques are used by researchers in many scientific fields (Olden et al.

34 2008). A variety of examples have previously shown that ML algorithms are more robust than

35 traditional regression-based models (Guisan and Zimmermann 2000). ML algorithms have also

36 been applied in predictive studies of fish stock recruitment (e.g., Bayesian networks in Fernandes

37 et al. 2013, 2015; and artificial neural networks in Krekoukiotis et al. 2016). However, the

38 applications of these algorithms in studies on fish ecology are still rare (Smoliński and Radtke 39 2017).

One of the ML techniques that has become increasingly popular is the random forest (RF)

41 algorithm, which combines many single regression trees into an ensemble (Breiman 2001).

42 Regression trees are used because they are efficient at selecting relevant predictors and can

43 handle interactions (Elith et al. 2006). Moreover, regression trees can deal with different types of

44 variables (e.g., categorical, numerical, dissimilarity matrices) and manage missing values with a

45 minimal loss of information (De'ath 2007). A comparison of different models has shown the

46 outstanding properties of RF in solving real world analytical problems (Fernández-Delgado et al.

47 2014). 
The application of RF may be valuable for obtaining information on biotic and abiotic

49 factors that affect marine fish (Smoliński and Radtke 2017). RF algorithm design makes it

50 possible to estimate variable importance by simulating how much worse the prediction will be in

51 the case of randomly permuted data for a selected predictor. Comparing the results for all

52 predictors provides information on the relative importance of each variable (Prasad et al. 2006).

53 A recent improvement of methods for variable selection is the Boruta algorithm (Kursa and

54 Rudnicki 2010). This method was designed as an RF wrapper for identifying all relevant

55 predictors, i.e., predictors shown by a statistical test to be more relevant than random probes. The

56 Boruta approach appears to be useful for ecological investigations, in which the number of

57 variables often exceeds the number of observations, thus hindering the robust selection of

$58 \quad$ variables for a final predictive model.

If the variables used in the modeling are represented in a temporal scale, an additional

60 selection of a time window for each predictor is necessary. A brief review of studies on the

61 relationships between fish recruitment and climatic conditions revealed that a priori selected

62 time windows are usually considered in the investigations. However, there are potentially many

63 plausible competing environmental signal hypotheses (van de Pol et al. 2016). Recent studies

64 have highlighted that climatic effects on organisms are likely complex and the identification of

65 optimal signals may be a nontrivial task (Kruuk et al. 2015). A variety of potential time windows

66 may be considered with "sliding window" analyses, which helps identify the optimal

67 environmental signals via a statistically sound exploratory method (van de Pol et al. 2016).

68 Because of the aforementioned advantages of RFs, their incorporation into the framework of

69 "sliding window" technique appears to be promising step in the development of tools for the

70 quantification of biological responses to environmental variability. 
In this paper, the influence of different biological and environmental drivers on small

72 pelagic fish recruitment will be considered using the example of main herring (Clupea harengus)

73 and sprat (Sprattus sprattus) stocks in the Baltic Sea (ICES 2016). Environmental conditions

74 have been suggested as determinants of fish recruitment via direct and indirect impacts; thus,

75 effects may occur with different time lags. Random forests (Breiman 2001) and the Boruta

76 algorithm (Kursa and Rudnicki 2010) were incorporated into the "sliding window" framework

77 that was previously proposed for linear models (van de Pol et al. 2016) to test these phenomena

78 in a systematic and statistical manner.

79 MATERIALS AND METHODS

$80 \quad$ Study area and species

81 The Baltic Sea is a semi-enclosed, shallow and brackish basin located in northern Europe (Fig.

82 1). The hydrological conditions within the Baltic are strongly dependent on sea water exchanges

83 through the Danish Straits, which are the only connection with the Atlantic Ocean (Lehmann et

84 al. 2002). A major reorganization of the Baltic ecosystem regime was observed in the late 1980s

85 (Möllmann et al. 2009), and it was driven mainly by large-scale climatic forcing, which led to warmer and less saline conditions that considerably affected all trophic levels (Alheit et al. 2005). The trophic network of the Baltic Sea is relatively simple and presents three main fish species: cod (Gadus morhua), herring and sprat, which constitute $\sim 80 \%$ of the total fish biomass (Margonski et al. 2010).

The subjects of the present study are two main Baltic pelagic stocks: i) herring in

91 subdivisions of the International Council for the Exploration of the Sea (ICES) 25-29 and 32

92 (excluding 28.1, i.e., Gulf of Riga); and ii) sprat in subdivisions 22-32 (Fig. 1; ICES 2016).

93 Previous studies have revealed that models of the relationships between spawning stock biomass

94 and recruitment for Baltic herring and sprat explain only a small portion of the year-to-year 
95

96

97

98

99

100

101

102

103

104

105

106

107

108

109

110

111

112

113

114

115

116

117

recruitment variability (e.g., Köster et al. 2003; MacKenzie and Köster 2004; Cardinale et al. 2009; Margonski et al. 2010). Thus, it was hypothesized that environmental drivers, such as hydroclimatic conditions and interactions with other fish species, as well as the biological characteristics of spawners may significantly affect the recruitment processes of these stocks.

\section{Data}

The recruitment abundance index (R; Fig. S1), the spawning stock biomass (SSB; Fig.S1) and weight at age groups (WAA; Fig. S2) of herring and sprat, and the total biomass (TSB; Fig. S3) of cod stocks in subdivisions 25-32 were obtained from the official ICES sources listed in Table 1. The R and SSB estimates for the period 1974-2016 were obtained from the results of virtual population analyses, which are calculated based on commercial catch data tuned by research-vessel survey data (ICES 2016). This method relies on assumptions of accurate reporting of catch data and information on biological parameters of the stock. Thus, the obtained estimates may be uncertain and could introduce variability to the analyses of stock recruitment (MacKenzie and Köster 2004). The weight by age groups was considered a proxy for fish condition, which for mature (spawning) individuals, is also significantly correlated with egg number (MacKenzie and Köster 2004). Information on the cod stock biomass was included in the analysis because of this species' role as a main predator of pelagic fish in the Baltic Sea ecosystem (Cardinale et al. 2009).

Two additional environmental predictors represented at a higher temporal resolution were incorporated in the modeling of recruitment: sea surface temperature (SST; Fig. S4a) and Baltic Sea Index (BSI; Fig. S4b). Temperature data were obtained from the Extended Reconstructed Sea Surface Temperature (ERSST v4) model (Huang et al. 2015). The ERSST v4 is a monthly dataset produced on a $2^{\circ} \times 2^{\circ}$ grid, and it is spatially complete for global oceans. Average 
118 monthly temperatures for the area $52-67^{\circ} \mathrm{N}, 10-31^{\circ} \mathrm{E}$ were used as a proxy of thermal conditions

119 for the investigated stocks. In addition, the BSI, which is a proxy of water mass circulation

120 within the central Baltic Sea, was used (Lehmann et al. 2002). This proxy is highly correlated

121 with North Atlantic Oscillation but regionally adjusted to the characteristic of the Baltic Sea, and

122 it is calculated as the normalized sea level pressure difference between Oslo, Norway $\left(53^{\circ} 13^{\prime} \mathrm{N}\right.$,

$\left.12314^{\circ} 13^{\prime} \mathrm{E}\right)$ and Szczecin, Poland (59 $\left.30^{\prime} \mathrm{N}, 10^{\circ} 30^{\prime} \mathrm{E}\right)$ (Fig. 1). Possible short-term direct influences

124 (e.g., by physiological responses) and long-term indirect effects (e.g., by food supply) of both

125 environmental variables were hypothesized; thus, different time lags were considered in the

126 analysis.

127 Data analysis

128 The entire analytical process was conducted separately for herring and sprat using $\mathrm{R}$ as the 129 response variable. For each stock, the set of explanatory variables covered the SSB and WAA of 130 the modeled stock, the recruitment abundance and SSB of the competitive pelagic stock, and the 131 TSB of cod (Table 1). Prior to the analysis, two missing cod TSB values were compensated for 132 with an iterative imputation method based on a RF (Stekhoven and Bühlmann 2012). Because 133 missing values were filled using the multicollinearity of the surrounding cells, this approach 134 allows for the entire database to be used in the analysis and increases the statistical power 135 without introducing spurious relationships between explanatory and response variables (Di 136 Franco et al. 2016).

137 The general approach used in the present work for the identification of optimal 138 environmental signals (Fig. 2) followed the "sliding window" technique proposed by van de Pol 139 et al. (2016). The protocol of this stepwise systematic method allows for the rigorous 140 identification of the best time window of predictors that are represented at a higher temporal 
141 resolution. The first step of this analysis is the construction of a baseline model without the 142 effects of the tested variables (e.g., hydroclimatic factors). Here, only biological variables were 143 used to construct baseline model (Table 1). Then, a set of candidate models are listed by 144 identifying all competing hypotheses (time windows of hydroclimatic factors) that require 145 testing. Finally, comparisons between all models are conducted to identify the optimal predictor 146 (variable with a critical time window) (Bailey and van de Pol 2016; van de Pol et al. 2016). In the present study, absolute time windows were used to sequentially test each environmental predictor (SST and BSI), and the reference date was defined as the end of the 149 spawning year. All possible combinations of time windows were considered within the range of 15036 months before this date. For each time window, the arithmetic mean was used as an aggregate 151 statistic of environmental conditions, and variables calculated in this manner were added to the 152 set of biological predictors (Table 1).

Then, the Boruta algorithm (Kursa and Rudnicki 2010) and RFs were applied to the 154 whole dataset in each time window to test the relevance of the added hydroclimatic predictors 155 (BSI or SST). Original RF algorithm builds the regression trees based on bootstrapped samples, 156 which are separated into training subsets (two-thirds of the samples), and remaining out-of-bag 157 subset (OOB, one-third of the samples) (Breiman 2001). OOB is used for assessing the 158 performance of the currently developed tree: to estimate the prediction error and to evaluate 159 variable importance. Loss of model accuracy (the decrease in \% of explained variance) from 160 permuting the values in each variable is measured. Z-scores are then calculated by dividing the 161 average loss of model accuracy by its standard deviation and used as importance measures for 162 variables in the RF ensemble model. Boruta, designed as an RF wrapper, extends this idea and 163 determines the relevance of variables via iterative comparisons of the importance of real 
164 variables and random probes, which are called shadow attributes. They are created by shuffling 165 the original variables in each algorithm iteration to form external reference for decision whether 166 the importance of any given variable is statistically significant (discernible from importance 167 which may arise from random fluctuation). For this reason, minimal, average and maximum Z168 scores of added shadow attributes are calculated. Variables with significantly lower importance 169 than maximum Z-score of shadow attributes are considered irrelevant (rejected), whereas those 170 with higher importance are selected as relevant (confirmed) (Kursa and Rudnicki 2010). This 171 extensive procedure was the basis for determining whether the environmental signal (mean SST 172 or BSI from a specific time window) is the relevant predictor. Whole process have been repeated 173 for each potential time window in the sliding window analysis. Because the number of Boruta 174 iterations was limited to 500 for the sake of computational efficiency, certain variables in the 175 model may be left without a decision (tentative). Such predictors were arbitrarily assumed to be 176 relevant and included in the next step of the analysis. This decision had no effects on the results 177 of environmental signal identification during sliding window stage. Misclassification of environmental signal may occur in this step of the sliding window 179 analysis by chance due to the large number of time windows considered. To evaluate directly the 180 method performance, series of tests were conducted on the artificial datasets. The goal of the 181 simulation was to assess the probability of false-positive and false-negative errors in the 182 classification of environmental signal by Boruta algorithm. For this purpose 1000 artificial 183 datasets, containing one response and one explanatory (environmental) variable, were generated 184 for each level of known correlation between variables: $\mathrm{R}^{2}=0$ (no environmental signal), $0.2,0.4$, 185 0.6, and 0.8 (strong environmental signal). Moreover, in order to consider differences in method 186 performance under a variety of sample sizes, simulations with $\mathrm{N}=10,20,30,42,60,100,200$, 
187400,800 and 1000 were carried out, giving 55000 simulation runs in total. In each run the Boruta 188 algorithm was used to classify environmental signal as true (relevant) or not. The rate of false189 negatives was calculated as the proportion of runs where dataset contained true signal $\left(\mathrm{R}^{2} \geq 0.2\right)$, 190 but algorithm rejected environmental variable. The rate of false-positives was calculated as the 191 proportion of runs where the dataset contained no signal $\left(\mathrm{R}^{2}=0\right)$, but the algorithm classified the 192 environmental variable as relevant. In the real example random forest models (Breiman 2001) were fitted for each time 194 window using relevant predictors identified by the Boruta method in the previous step. The 195 accuracy of the models was checked via 5-fold cross-validations repeated 100 times (Kuhn 196 2008), and the same training and test sets were used in each considered time window to make 197 results comparable. The root mean squared error (RMSE) metric was calculated as a predictive 198 performance measure of the models and used for optimal signal selection. The time window with 199 the lowest RMSE (the lowest unexplained variance of recruitment) was selected. Two iterations 200 of the entire "sliding window" analysis were conducted for each hydroclimatic variable, wherein 201 the second step models were refitted with incorporation of the first (optimal) determined signal. 202 Such an approach was motivated by the expected multiple signals of environmental variables, 203 which may drive fish recruitment with different time lags (e.g., short-term and long-term 204 effects), and it allows for the identification of secondary, suboptimal time windows of 205 environmental variables.

The four best-supported environmental signals for each stock (two time windows for each

207 of the two hydroclimatic predictors) were added to the dataset, and all predictors were retested 208 with the Boruta algorithm, assuming that possible interactions may occur between newly added 209 variables and cause changes in their relative importance. Then, the predictors selected by the 
210 Boruta algorithm (confirmed and tentative) were incorporated into the final RF model. The

211 predictive abilities of this model were compared with RFs based on biological variables only

212 (Table 1), SSB and hydroclimatic signals or SSB only. Additionally, traditional Ricker stock-

213 recruitment model and modified Ricker models with inclusion of identified hydroclimatic signals

214 as controlling effects (Iles and Beverton 1998) were tested in terms of predictive performance.

215 Curves were fitted using minimum least squares nonlinear regression. Optimal set of 216 environmental factors in the modified Ricker models were selected based on the Akaike 217 Information Criterion (AIC) obtained during the preliminary tests on the whole datasets. The 5218 fold cross-validation was repeated 100 times, and the values of $25^{\text {th }} 50^{\text {th }}$ (median) and $75^{\text {th }}$ 219 percentile of the $\mathrm{R}^{2}$ metric distribution were used for the comparisons.

RF algorithms generate additional information, which is often underutilized (Touw et al.

221 2013). For example, during the training of RF observations are recursively partitioned into the 222 nodes of trees (Breiman 2001). Thus, the proximity between two observations can be calculated 223 as the proportion of the time that the observations occur in the same terminal node of a tree to the 224 number of trees in the entire RF ensemble (Cutler et al. 2012). This feature allows to obtain the 225 proximity between samples and extract relevant trends from data with complex variable 226 relationships (Touw et al. 2013). A principal component analysis (PCA) was conducted on the 227 proximity matrix of the final model for all observations (recruitment years) in the dataset. Scores 228 of the first two components were visualized to assess the similarities between recruitment years 229 and for potential class discovery from RF clustering.

230 To evaluate the relationships between the response and selected environmental predictors, 231 partial dependence plots were obtained, and they reflect the marginal effects of particular 232 variables on the response within the RF model (Hastie et al. 2009). Prediction intervals were 
233 calculated using the mean \pm one and two standard deviations of all predictions obtained from 234 individual trees in the RF ensemble (Freeman et al. 2010).

236 analysis, two-thirds of the variables available in each step were used for the construction of each 237 regression tree, whereas in the final model, this parameter (mtry) was tuned via cross-validation. 238 The Boruta (Kursa and Rudnicki 2010), randomForest (Liaw and Wiener 2002), ranger (Wright 239 and Ziegler 2015) and caret (Kuhn 2008) packages in the $R$ scientific computing environment (R

240 Development Core Team 2011) were used in the study.

\section{RESULTS}

242 A slow decline of herring SSB was observed between 1974 and 2000 from approximately 1.7 to

2430.4 million tons, and then an increase occurred in the remaining period up to 1 million tons in

244 2015. Herring recruitment at age 1 fluctuated at approximately 17 billion individuals during the

245 investigated period and did not show a clear trend. The SSB of sprat increased between 1990 and

2461996 to almost 2 million tons and then slowly decreased. Sprat recruitment at age 1 increased in

247 the early 1990s similar to the SSB trend. Starting in 1995, a decreasing trend was observed, and 248 then three strong recruitment years occurred: 2004, 2009 and 2015. The mean weight of 249 individuals in all age groups decreased by approximately 30-40\% between 1985 and 1995 for 250 herring and by approximately $40-60 \%$ during the 1990 s for sprat stock. The total biomass of the 251 cod stock in ICES subdivisions 25-32 decreased during the 1980s from 1 million tons to 252 approximately 0.16 million tons and fluctuated around this value until the end of the observed 253 period.

254 According to the simulation results, the rate of false-positive classifications of 255 environmental signal by Boruta algorithm was lower than 0.05 for all generated datasets (Fig. 3).

256 The probability of such misclassification increases with increasing sample size up to $N=30$, but 
257 remain relatively stable for the datasets with more observations. The probability of false258 negatives was above 0.05 for small datasets (10 samples) and correlations between $\mathrm{R}^{2}=0.2$ and $259 \mathrm{R}^{2}=0.6$. When simulated signal was low $\left(\mathrm{R}^{2}=0.2\right)$ in the datasets containing 30 or less samples, 260 it was relatively often rejected by Boruta. In contrary, strong signal $\left(\mathrm{R}^{2}=0.8\right)$ was detected in 261 most cases and even for the datasets containing 10 samples misclassification rate was on the 262 level of 0.013.

The "sliding window" analysis conducted on the real data showed that the two best264 supported time windows during which mean BSI influenced herring recruitment were as follows: 265 i) 24-14 months before the reference date (end of the spawning year) and ii) the previous 16 266 months before this date (Table 2, Fig. 4a-b). The most significant effects of SST for herring 267 stock recruitment were identified for the following periods: i) 9-5 months and ii) 22-21 months 268 before the end of the spawning year (Table 2, Fig. 4c-d). The BSI at i) 11-9 months and ii) $19^{\text {th }}$ 269 months before the reference date and the SST at i) 4-3 months and ii) 32-23 months before the 270 end of the spawning year were identified as the best environmental signals for predicting sprat 271 recruitment (Table 2, Fig. 4e-h). The RMSE of the models in certain adjacent time windows was 272 nearly as low as that of the identified optimal signals because of the temporal autocorrelation of 273 hydroclimatic variables and similar sizes of their ecological effects (Fig. 4).

The results of the statistical tests conducted with the Boruta algorithm revealed that 275 among the biological predictors and environmental signals created in the previous step, certain 276 variables were relevant for the prediction of Baltic pelagic fish recruitment (Fig. 5). The most 277 important predictors for herring were the optimal BSI signal, WAA 3, TBS of cod and 278 recruitment of sprat. Boruta rejected the WAA 1,8 and 5 from the herring model and the second 279 signal of SST identified during the "sliding window" analysis (Fig. 5a). Similarly, the optimal 
280 SST and both BSI signals were indicated as the best predictors for sprat recruitment success.

281 High importance was also demonstrated for the sprat WAA 1-3 and 6. Boruta rejected the 282 following variables: WAA 4 and 5, herring recruitment, herring SSB and second SST signal 283 identified during the "sliding window" tests (Fig. 5b).

Tuning RFs (grown on a set of relevant variables identified by Boruta) with repeated 5fold cross-validations showed that the optimal numbers of variables used to build each tree in the 286 ensemble (mtry parameter) were 4 and 7 for the herring and sprat recruitment models, respectively. The PCA calculated on the proximity matrix of final RF models revealed major 288 alterations in the recruitment processes between the years 1989 and 1990 for both investigated pelagic stocks (Fig. 6). The recruitment years before and after the shift formed two distinct groups on the PCA plots. One exception was sprat recruitment in 1976, which was more similar to the recruitment years after the identified reorganization (Fig. 6b). the RFs revealed contrasting effects of different signals associated with the same variable. The 294 long-lag effect of the optimal BSI signal (mean value from months $24-14$ before the end of the 295 spawning year) on herring recruitment was negative, whereas the short-lag effect of this variable 296 (mean of the 16 months before the reference date) was positive (Fig. 7a). Similarly, the short-lag 297 effect of BSI in the optimal window (11-9 months before the reference) had a positive effect on 298 sprat recruitment, whereas the long-lag effect $\left(19^{\text {th }}\right.$ months before the reference) was negative 299 (Fig. 7c). In both cases, the threshold levels of BSI, which had a considerable influence on 300 recruitment success, were observed. According to the model predictions, herring recruitment 301 increases abruptly when the optimal BSI predictor drops below -0.1. A similar effect was 302 observed when the mean BSI from the second time window exceeded 0.05. Sprat recruitment 
303 increased sharply when the optimal BSI reached positive values and decreased when the mean

304 BSI for the second time window was higher than -0.35 . The recruitment of herring stocks

305 showed a nonlinear positive response to the optimal SST signal, which was calculated as the

306 mean value from the period March-July (Fig. 7b). For sprat, a positive relationship was observed

307 between stock recruitment and the optimal SST (mean from the period August-September), with

308 a clear threshold value observed at approximately $15.7^{\circ} \mathrm{C}$ (Fig. $\left.7 \mathrm{~d}\right)$.

309 The final RF models for herring and sprat were significantly improved by the addition of

310 environmental variables. The accuracy obtained in the cross-validations for models that

311 considered all relevant variables (with identified hydroclimatic signals) exceeded the accuracy of

312 the models that incorporated only biological variables and RF models of the relationship between

313 recruitment and SSB (Table 3). However, RF model fitted for sprat on identified hydroclimatic

314 signals and SSB revealed even higher predictive performance, than RF with all relevant variables

315 (including also biological covariates). The observed improvement from the incorporation of

316 hydroclimatic predictors was high for herring stock (from median $\mathrm{R}^{2}=0.45$ to median $\mathrm{R}^{2}=0.65$ )

317 and even higher for sprat (from median $\mathrm{R}^{2}=0.10$ to median $\mathrm{R}^{2}=0.51$ ). According to AIC values

318 inclusion of two optimal hydroclimatic signals (first SST and first BSI) as controlling effects in

319 the Ricker function was statistically supported for both stocks (Table S1, Table S2). Traditional

320 stock-recruitment models obtained higher $\mathrm{R}^{2}$ scores than RF if only SSB was taken into account

321 as recruitment predictor. In contrary, RF models obtained higher predictive abilities than Ricker

322 models when hydroclimatic variables were also included (Table 3).

323

The values predicted by the final RF models were underestimated in certain years when

324 strong recruitment occurred (often referred to as spiked recruitment), especially in the case of the 
325 sprat stocks (Fig. 8). All observed values ranged in the uncertainty area of \pm 1 standard deviations

326 for all individual tree predictions in the ensemble model.

\section{DISCUSSION}

328 Relatively few ML applications can be found in ecology field compared with other disciplines

329 (Olden et al. 2008). In particular, the relationships between recruitment success and 330 environmental conditions have been investigated for many fish species using linear models (e.g.,

331 Cardinale et al. 2009; Margonski et al. 2010; Lindegren and Checkley 2013); however, 332 applications of RF for these purposes are still rare (e.g., Hansen et al. 2015) despite the 333 suitability of this modeling technique for such applied research because of its robustness and 334 accuracy (Stekhoven and Bühlmann 2012). By incorporating bootstrap techniques, the RF 335 algorithm shows good performance even when the number of predictors exceeds the number of 336 observations (Díaz-Uriarte and Alvarez de Andrés 2006). The opportunity to test a large number 337 of predictors within one model is considered a prominent feature of RF, and this algorithm may 338 be especially helpful in recruitment modeling, where the number of observations (recruitment 339 years) is often limited, thus preventing parameter estimations by more complex linear models 340 with multiple predictors, such as Generalized Additive Models or Generalized Linear Mixed 341 Models. Moreover, the general design of the RF algorithm helps obtain additional knowledge 342 from the data, such as the variable importance for further selection of relevant predictors, 343 proximity scores to investigate possible clusters of observations or partial dependence plots to 344 visualize the main relationships between response and exploratory variables (Touw et al. 2013).

345 The advantages of the RF method have been used in this work for the selection of optimal 346 hydroclimatic predictors of fish recruitment. The application of ML techniques for optimal signal

347 identification was recommended by van de Pol et al. (2016), who developed a tool for "sliding 
348 window" analyses within the framework of linear models. This exploratory method can be used

349 to test different hypotheses (time windows) of environmental effects on ecological processes. In

350 particular, variations in fish recruitment have often been considered an indirect response to

351 changes in an additional driver (Drinkwater 2005). Thus, the a priori selection of only a single

352 time window of potential predictors with limited knowledge, which is often the case in

353 recruitment modeling, may miss relevant information. Although highly complex environmental

354 influences on biological processes increase the difficulty of such analyses (Kruuk et al. 2015),

355 the exploratory methods of signal identification presented here may facilitate the non-arbitrary

356 selection of optimal time windows for investigated variables.

Misleading correlations between biological processes, such as recruitment and

358 environmental data, are general statistical problem, since existence of a correlation does not

359 imply the causation (Gulland 1952). Moreover, testing of large number of potential

360 environmental signals (time windows) in the "sliding window" analysis leads to inevitable

361 occurrence of false-positive signals, which can be found by chance. For this reason, the

362 importance of conducting simulation tests to demonstrate, that novel method can correctly

363 identify known signal is emphasized (Teller et al. 2016). Evaluation of method performance with

364 known environmental signal and different sample sizes should be a first step towards identifying

365 the potential pitfalls (Bailey and van de Pol 2016; van de Pol et al. 2016).

In this study datasets used for simulations were generated with assumption of simple

367 linear relationships between two variables. No multiple interacting or confounding variables

368 were taken into account (van de Pol et al. 2016). However, tree-based methods, like random

369 forests, may handle such complex interactions between variables and non-linear relationships

370 between them (Cutler et al. 2012). These features favor random forests as predictive technique, 
371 giving extraordinary accuracy, but may also cause oversensitivity in detecting signals and

372 patterns. Effective tests of signal relevance, that reduce rate of false-positive errors, is the general

373 aim, which may be achieved with proposed application of Boruta algorithm. Boruta performs a

374 top-down search for relevant variables. It compares original variable importance in the random

375 forest model with importance of its randomized copies, providing unbiased and stable selection

376 of important features (Kursa and Rudnicki 2010). Simulations conducted in the presented work

377 revealed, that the probability of false-positive misclassification of environmental signal is

378 relatively low, maintaining the level below 0.05 . Also the rate of false-positives was on the low

379 level for most of cases, showing high ability of signal detection by the random forests. However,

380 because both types of errors seem to be unavoidable, results of environmental signal analysis

381 based on proposed data-mining method should be taken with special care. Observational

382 correlation studies are valuable tools to detect general ecological relationships and to generate

383 new hypothesis, but more complete description of mechanisms of pelagic fish recruitment need

384 further process-oriented experiments in the laboratory or in the field (Baumann et al. 2006).

$\mathrm{R}$ and SSB used in the presented study were obtained from virtual population analysis

386 conducted based on commercial catch data, which are tuned by research-vessel survey data

387 (ICES 2016). Reported landings and biological parameters assumed in the model can be

388 imprecise and influence the stock assessment process (MacKenzie and Köster 2004). However,

389 conducted analyses of residuals, retrospective patterns and sensitivity suggest appropriateness of

390 the structural assumptions of Baltic herring and sprat assessment models (ICES 2016). Besides

391 relatively high quality of representation of underlying populations and fishery processes, results

392 of post hoc analysis based on R and SSB estimates derived by virtual population analysis, rather

393 than raw data, should be taken with caution (Brooks and Deroba 2015). Cross-validation applied 
394 in the presented study help to explore uncertainty associated with outlying data points with high

395 leverage and assess predictive abilities of RF recruitment models giving a measure of the likely 396 reliability of their application (Francis 2006). Additional tests repeated using confidence 397 intervals of final estimates, results from stock assessment sensitivity analysis or retrospective 398 runs are advised to address more directly different sources of uncertainty (Brooks and Deroba 399 2015).

By identifying multiple signals for the same environmental variable, different long-lag 401 and short-lag effects on the investigated processes may be detected. The analysis revealed 402 contrasting effects of the BSI from different time windows on the recruitment of herring and 403 sprat. Positive BSI values in the period from August-December in the year preceding the 404 spawning season or from January-March in the year of spawning had positive effects on the 405 recruitment success of herring and sprat, respectively. High BSI values correspond to westerly 406 winds over the Baltic, which transport warm and humid air masses to the Baltic region and result 407 in higher sea surface temperatures (Lehmann et al. 2002; Möllmann et al. 2009), which may 408 promote the reproduction of pelagic fish. Similar significant effects of relatively short-time 409 signals of BSI on fish recruitment were also found in other studies of Baltic herring stocks 410 (Cardinale et al. 2009; Gröger et al. 2014).

The results presented in this paper also indicate the possible occurrence of a long-term 412 BSI signal, which has the highest importance in the herring recruitment model and was 413 considered a suboptimal signal in the sprat recruitment model. Low BSI values had long-term 414 positive effects on fish recruitment and the observed relationships varied with short-term BSI 415 signals. Although interpreting such delayed effects identified by exploratory analyses may be 416 difficult (Kruuk et al. 2015), these effects suggest the possible occurrence of indirect cascading 
417 effects in the ecosystem through the succession of changes from climate to abiotic environment 418 to biotic environment to fish reproduction success, which may be delayed by long "signal 419 travelling times" (Gröger et al. 2014). Because low BSI and NAO values are correlated with 420 higher salinity in the Baltic Sea (Hänninen et al. 2000; Möllmann et al. 2003), it is assumed that 421 these saline and oxygen rich waters may stimulate the production of the ecosystem prior to the 422 spawning year and may influence spawner conditions, the further production of eggs, as well as 423 indirectly reduce mortality of the larvae and early juveniles.

The analyses performed here suggested that recruitment of the investigated stocks is 425 driven by temperature conditions. The SST from March to July in the spawning year was 426 considered one of the relevant predictors of herring recruitment success and had intermediate 427 importance. Depending on the locality, the spring spawning peak of herring in the Baltic Sea was 428 observed between March and July (Rajasilta 1993; Podolska et al. 2006), and the thermal 429 conditions during this period may have influenced the recruitment success of the stock. Cardinale 430 et al. (2009), Margonski et al. (2010) and Bartolino et al. (2014) have demonstrated that the 431 August SST has significant influence on herring recruitment. However, in these studies, only the 432 mean temperatures from the selected months were tested in the framework of Generalized 433 Additive Models. The number of hypothesized time windows of temperature variables were 434 limited because of the problems associated with candidate predictor collinearity or a priori 435 assumptions.

The SST from August to September in the year of spawning constituted the best predictor of sprat recruitment. The temperature of the surface water masses during August was also found to be the most significant predictor of sprat recruitment based on detailed correlation tests of the 439 stratified-by-depth monthly means of the thermal conditions in the Baltic Sea (Baumann et al. 
440

441

442

443

444

445

446

447

448

449

450

451

452

453

454

455

456

457

458

459

460

461

462

2006). Voss et al. (2012) noted that sprat larval growth accelerates in May, is high in July and August, and slows from September onwards. These results may confirm the earlier conclusions that assumed a high contribution of individuals born late in the season in the Baltic sprat recruitment and the importance of processes observed during the late larval and early juvenile stages (Baumann et al. 2006). Results obtained in this study revealed, that temperature observed earlier in the year has also relatively high influence on sprat recruitment success. Peak spawning of sprat in the Baltic Sea is observed in April - June (Karasiova 2002) and is followed by 50-90 days of larval stage (Arrhenius and Hansson 1993). Thermal conditions in in the early part of the year may affect sprat recruitment e.g. by direct effects on sprat growth, mortality, maturation and egg production rates, as well as indirectly by reducing or stimulating spring production of zooplankton, which further constitutes essential prey for larvae and adult sprat (MacKenzie and Köster 2004; Baumann et al. 2006; MacKenzie et al. 2008).

The development of universal predictive models of fish recruitment for the entire investigated period (1974-2016) may be less efficient because of the regime shift of the Baltic Sea ecosystem that occurred in the late 1980s (Alheit et al. 2005; Möllmann et al. 2009). Abrupt alterations in the abiotic conditions of the Baltic Sea driven by phase transitions of the NAO and BSI caused the reorganization of the ecosystem structure and functioning (Möllmann et al. 2009), which promoted profound changes in the plankton communities and caused reactions of fish stocks by bottom-up mechanisms (Alheit et al. 2005). In the present study, the PCA conducted on the proximity matrix of the RF model revealed significant differences in herring and sprat recruitment in the years before and after 1989-1990. Reorganization of the ecosystem driven by large-scale climatic factors could have potentially changed the nature of the relationships between the recruitment of the studied species and environmental conditions. 
463 Further modeling of stock recruitment should focus on the regime-specific drivers of these 464 processes and possible differences in the relationships observed in each regime. Because RF 465 algorithms are generally data-driven techniques, they may lose their predictive ability if values of 466 variables go well beyond the range observed in the data (e.g. after strong alteration of 467 environmental conditions). However, potentially RF may help to early identify changes in stock468 recruitment-environment relationships by internal determination of similarity between samples 469 (recruitment years) during development of regression trees ensembles (Touw et al. 2013). 470 Preliminary analysis conducted on the presented datasets (not shown in this paper) suggested, 471 that these properties of RF may be beneficial for identification of recent changes, but need to be 472 tested in the future studies, taking into account different baselines from the longer time series, 473 including various ecosystem states. The structure of zooplankton communities and food supply affect the spawners and 475 recruits of pelagic fish and are considered significant predictors of recruitment success (Köster et 476 al. 2003; Cardinale et al. 2009; Raid et al. 2010). In this study, information on the feeding 477 conditions were indirectly presented in the dataset as the mean weight of the individuals at age 478 groups assuming a correlation between these variables. However, further inclusion of data on 479 zooplankton availability for spawning individuals and early stages of fish may significantly 480 improve the accuracy of the model. Moreover, only the two best signals of the variables were 481 added sequentially based on the results of the optimal climatic signal detection. Because RF and 482 many other ML techniques can handle correlated variables, robust predictions may be conducted 483 based on a broader set of potential predictors, e.g., a high number of environmental signals 484 coming from different time windows. A more restricted approach was applied in this study to 
485 obtain a reasonable balance between the predictive accuracy and ecological interpretability of the 486 model (Hansen et al. 2015).

One can expect that exclusion of tentative variables in the final step of the analysis may 488 increase the accuracy of the prediction due to the elimination of noise (Kursa and Rudnicki 489 2010). Subsequent model building based on subsets of variables in the minimal-optimal fashion 490 (Genuer et al. 2008) may also improve the predictive performance of RFs. Even though it was 491 not the ultimate goal of this study, comparisons of the models showed, that RF of sprat 492 recruitment limited to the hydroclimatic signals and SSB achieved better predictive results than 493 the full model (including also biological factors). Nevertheless, developed RFs showed better 494 performance than traditional and modified Ricker models. A main drawback of the majority of 495 traditional methodologies for incorporating environmental factors into stock-recruitment models 496 is the fact that investigated dependencies are usually non-linear and asymmetrical (Subbey et al. 497 2014).

This study demonstrated that the incorporation of environmental hydroclimatic variables 499 into recruitment models significantly improved the prediction accuracy. More accurate 500 recruitment predictions can advance annual stock assessments and advice; however, the number 501 of fish stocks managed with respect to environmental conditions is still limited (MacKenzie et al. 502 2008). The current methods applied to perform recruitment estimates of the investigated Baltic 503 pelagic stocks are based on a simple calibration regression and combination method (Shepherd 504 1997), and this approach neglects the variability of conditions in the marine environment (ICES 505 2016). Because data on environmental variables identified in the presented study as the best 506 predictors of fish recruitment may be partly unavailable for forecasting during annual fishery 507 advisory meeting due to the agreed schedule of works, future search of predictors may be 
508 restricted to the period that give chance to obtain appropriate data in advance before assessment

509 meetings and to implement them in the routine stock assessment procedures (MacKenzie et al.

510 2008). Such actions could increase the accuracy of predictive models of recruitment for year

511 classes that will enter the fishery in the near future (Subbey et al. 2014), could help to provide

512 such predictions earlier, giving management organizations and industry more time to adapt to

513 changes in fish production (MacKenzie and Köster 2004) or could be applied in simulation

514 studies to explore population dynamics under different scenarios of environmental change

515 (MacKenzie et al. 2012).

516 In conclusion, the significant influence of SST on the recruitment processes of the

517 investigated stocks was confirmed. Moreover, contrasting effects of the mean BSI from two

518 different time windows were observed, which demonstrated that the same environmental variable

519 may have different short-term and long-term effects on biological processes. These results

520 highlighted that the incorporation of environmental factors in the assessment of stocks may

521 improve fishery management procedures. Such actions can be especially beneficial in areas that

522 are highly vulnerable to climate change, such as the Baltic Sea (HELCOM 2013), where the

523 strong influence of climatic variations on fish population dynamics is clear (MacKenzie et al. 524 2007).

525 The combination of RFs, the Boruta algorithm and a "sliding window" approach was 526 proposed for the selection of relevant predictors and identification of the optimal time window 527 for environmental variables at a monthly resolution. The extension of available statistical 528 techniques outside of traditional frameworks may improve the precision and accuracy of models 529 and could be used to resolve more complex ecological questions (Bolker et al. 2013). This ability 530 is particularly important now because the dynamic development of open-source environmental 
531 and biological databases allow for testing a variety of hypotheses; however, such approaches

532 require more flexible methods of statistical analysis. This paper highlights the potential benefits

533 of data mining and ML applications in ecological modeling and shows that the proposed

534 analytical approach may be valuable for the selection of relevant predictors and the investigation

535 of complex environmental impacts in a broad range of ecological studies.

536 ACKNOWLEDGEMENTS

537 This work resulted from the BONUS BLUEWEBS project which has received funding from

538 BONUS (Art 185), funded jointly by the EU, the Academy of Finland, Projektträger Jülich (PtJ),

539 Germany, the State Education Development Agency of Latvia, the National Centre for Research

540 and Development, Poland, and the Swedish Research Council Formas. The author would like to

541 thank the associate editor and reviewers for their valuable comments on the manuscript and

542 Professor Jan Horbowy for advice on traditional stock-recruitment-environment models.

\section{REFERENCES}

544 Alheit, J., Möllmann, C., Dutz, J., Kornilovs, G., Loewe, P., Mohrholz, V., and Wasmund, N. 2005. Synchronous ecological regime shifts in the central Baltic and the North Sea in the late 1980s. ICES J. Mar. Sci. 62(7): 1205-1215. doi:10.1016/j.icesjms.2005.04.024.

547 Arrhenius, F., and Hansson, S. 1993. Food consumption of larval, young and adult herring and $548 \quad$ sprat in the Baltic Sea. Mar. Ecol. Prog. Ser. 96: 125-137.

549 Bailey, L.D., and van de Pol, M. 2016. climwin: An R Toolbox for Climate Window Analysis. PLoS One 11: 1-27. doi:10.1371/journal.pone.0167980.

551 Bartolino, V., Margonski, P., Lindegren, M., Linderholm, H.W., Cardinale, M., Rayner, D., 552 Wennhage, H., and Casini, M. 2014. Forecasting fish stock dynamics under climate 553 change : Baltic herring (Clupea harengus) as a case study. Fish. Oceanogr. 23(3): 258-269. 
doi:10.1111/fog. 12060 .

555

556

557

558

559

560

561

562

563

564

565

566

567

568

569

570

571

572

573

574

575

576

Baumann, H., Hinrichsen, H.-H., Möllmann, C., Köster, F.W., Malzahn, A.M., and Temming, A. 2006. Recruitment variability in Baltic Sea sprat (Sprattus sprattus) is tightly coupled to temperature and transport patterns affecting the larval and early juvenile stages. Can. J. Fish. Aquat. Sci. 63(10): 2191-2201. doi:10.1139/f06-112.

Bolker, B.M., Gardner, B., Maunder, M., Berg, C.W., Brooks, M., Comita, L., Crone, E., Cubaynes, S., Davies, T., de Valpine, P., Ford, J., Gimenez, O., Kéry, M., Kim, E.J., Lennert-Cody, C., Magnusson, A., Martell, S., Nash, J., Nielsen, A., Regetz, J., Skaug, H., and Zipkin, E. 2013. Strategies for fitting nonlinear ecological models in R, AD Model Builder, and BUGS. Methods Ecol. Evol. 4(6): 501-512. doi:10.1111/2041-210X.12044.

Breiman, L. 2001. Random forests. Mach. Learn. 45: 5-32. doi:10.1023/A:1010933404324.

Brooks, E.N., and Deroba, J.J. 2015. When "data" are not data: the pitfalls of post hoc analyses that use stock assessment model output. Can. J. Fish. Aquat. Sci. 72(4): 634-641. doi:10.1139/cjfas-2014-0231.

Cardinale, M., Möllmann, C., Bartolino, V., Casini, M., Kornilovs, G., Raid, T., Margonski, P., Grzyb, A., Raitaniemi, J., Gröhsler, T., and Flinkman, J. 2009. Effect of environmental variability and spawner characteristics on the recruitment of Baltic herring Clupea harengus populations. Mar. Ecol. Prog. Ser. 388: 221-234. doi:10.3354/meps08125.

Checkley, D.M., Alheit, J., Oozeki, Y., and Roy, C. 2009. Climate Change and Small Pelagic Fish. In Cambridge University Press. doi:10.1017/CBO9780511596681.

Cushing, D.H. 1996. Towards a Science of Recruitment in Fish Populations. Excellence in Ecology. In Journal of Chemical Information and Modeling. Ecology Institute, Oldendorf/Luhe. doi:10.1017/CBO9781107415324.004. 
577 Cutler, A., Cutler, D.R., and Stevens, J.R. 2012. Random forests. In Ensemble Machine

578 Learning: Methods and Applications. Springer. pp. 157-175. doi:10.1007/978-1-4419-

579 9326-7.

580

581

582

583

584

585

586

587

588

589

590

591

592

593

594

595

596

597

598

599

De'ath, G. 2007. Boosted trees for ecological modeling and prediction. Ecology 88(1): 243-251. doi:10.1890/0012-9658(2007)88[243:BTFEMA]2.0.CO;2.

Díaz-Uriarte, R., and Alvarez de Andrés, S. 2006. Gene selection and classification of microarray data using random forest. BMC Bioinformatics 7: 3. doi:10.1186/1471-2105-73.

Dreyfus-León, M., and Chen, D.G. 2007. Recruitment prediction with genetic algorithms with application to the Pacific Herring fishery. Ecol. Modell. 203: 141-146. doi:10.1016/j.ecolmodel.2005.09.016.

Drinkwater, K.F. 2005. The response of Atlantic cod (Gadus morhua) to future climate change. ICES J. Mar. Sci. 62(7): 1327-1337. doi:10.1016/j.icesjms.2005.05.015.

Elith, J., Graham, C., Anderson, R., Dudik, M., Ferrier, S., Guisan, A., Hijmans, R., Huettmann, F., Leathwick, J.R., Lehmann, A., Li, J., Lohmann, L., Loiselle, B., Manion, G., Moritz, C., Nakamura, M., Nakazawa, Y., Overton, J., Peterson, A., Phillips, S., Richardson, K., Scachetti-Pereira, R., Schapire, R., Soberon, J., Williams, S., Wisz, M., and Zimmermann, N. 2006. Novel methods improve prediction of species' distributions from occurrence data. Ecography 29: 129-151. doi:10.1111/j.2006.0906-7590.04596.x.

Elith, J., Leathwick, J.R., and Hastie, T. 2008. A working guide to boosted regression trees. J. Anim. Ecol. 77(4): 802-813. doi:10.1111/j.1365-2656.2008.01390.x.

Fernandes, J.A., Irigoien, X., Lozano, J.A., Inza, I., Goikoetxea, N., and Pérez, A. 2015. Evaluating machine-learning techniques for recruitment forecasting of seven North East 
600

601

602

603

604

605

606

607

608

609

610

611

612

613

614

615

616

617

618

619

620

621

622

Atlantic fish species. Ecol. Inform. 25: 35-42. Elsevier B.V. doi:10.1016/j.ecoinf.2014.11.004.

Fernandes, J.A., Lozano, J.A., Inza, I., Irigoien, X., Pérez, A., and Rodríguez, J.D. 2013.

Supervised pre-processing approaches in multiple class variables classification for fish recruitment forecasting. Environ. Model. Softw. 40: 245-254.

doi:10.1016/j.envsoft.2012.10.001.

Fernández-Delgado, M., Cernadas, E., Barro, S., and Amorim, D. 2014. Do we Need Hundreds of Classifiers to Solve Real World Classification Problems? J. Mach. Learn. Res. 15: 31333181.

Francis, R.I.C.C. 2006. Measuring the strength of environment-recruitment relationships: the importance of including predictor screening within cross-validations. ICES J. Mar. Sci. 63(4): 594-599. doi:10.1016/j.icesjms.2006.01.001.

Di Franco, A., Thiriet, P., Di Carlo, G., Dimitriadis, C., Francour, P., Gutiérrez, N.L., Jeudy de Grissac, A., Koutsoubas, D., Milazzo, M., Otero, M. del M., Piante, C., Plass-Johnson, J., Sainz-Trapaga, S., Santarossa, L., Tudela, S., and Guidetti, P. 2016. Five key attributes can increase marine protected areas performance for small-scale fisheries management. Sci. Rep. 6: 38135 . doi:10.1038/srep38135.

Freeman, E. a, Frescino, T.S., and Moisen, G.G. 2010. ModelMap : an R Package for Model Creation and Map Production.

Genuer, R., Poggi, J.-M., and Tuleau, C. 2008. Random Forests: some methodological insights. Institut National de Recherche en Informatique et en Automatique, Paris, France.

Gröger, J.P., Hinrichsen, H.H., and Polte, P. 2014. Broad-scale climate influences on springspawning herring (Clupea harengus, L.) recruitment in the Western Baltic Sea. PLoS One 
9(2): 1-14. doi:10.1371/journal.pone.0087525.

624

625

626

627

628

629

630

631

632

633

634

635

636

637

638

639

640

641

642

643

644

645

Guisan, A., and Zimmermann, N.E. 2000. Predictive habitat distribution models in ecology. Ecol. Modell. 135: 147-186. doi:10.1016/S0304-3800(00)00354-9.

Gulland, J.A. 1952. Correlations on Fisheries Hydrography. J. du Cons. 18: 351-353.

Hänninen, J., Vuorinen, I., and Hjelt, P. 2000. Climatic factors in the Atlantic control the oceanographic and ecological changes in the Baltic Sea. Limnol. Oceanogr. 45(3): 703-710. doi:10.4319/1o.2000.45.3.0703.

Hansen, G.J.A., Carpenter, S.R., Gaeta, J.W., Hennessy, J.M., and Zanden, M.J. Vander. 2015. Predicting walleye recruitment as a tool for prioritizing management actions. Can. J. Fish. Aquat. Sci. 72: 661-672. doi:10.1139/cjfas-2014-0513.

Hastie, T., Tibshirani, R., and Friedman, J. 2009. The Elements of Statistical Learning - Data Mining, Inference. Springer Verlag. doi:10.1007/b94608.

HELCOM. 2013. Climate Change in the Baltic Sea Area, HELCOM thematic assessment in 2013. Balt. Sea Environ. Proc. 137: 54.

Huang, B., Banzon, V.F., Freeman, E., Lawrimore, J., Liu, W., Peterson, T.C., Smith, T.M., Thorne, P.W., Woodruff, S.D., and Zhang, H.M. 2015. Extended reconstructed sea surface temperature version 4 (ERSST.v4). Part I: Upgrades and intercomparisons. J. Clim. 28(3): 911-930. doi:10.1175/JCLI-D-14-00006.1.

ICES. 2013. Report of the Baltic Fisheries Assessment Working Group 2013 (WGBFAS), 10 17 April 2013, ICES Headquarters, Copenhagen. ICES CM 2013/ACOM:10.

ICES. 2016. Report of the Baltic Fisheries Assessment Working Group 2016 (WGBFAS), 12 19 April 2016, ICES Headquarters, Copenhagen. ICES CM 2016/ACOM:11.

ICES. 2017. ICES Spatial Facility. Available from http://geo.ices.dk/ [accessed 20 February 
646

647

648

649

650

651

652

653

654

655

656

657

658

659

660

661

662

663

664

665

666

667

668

2017].

Iles, T.C., and Beverton, R.J.H. 1998. In Collaboration with the Netherlands Institute for Sea Research Stock, recruitment and moderating processes in flatfish. J. Sea Res. 39: 41-55. doi:10.1016/S1385-1101(97)00022-1.

Karasiova, E.M. 2002. Variability of sprat peak spawning and larvae appearance timing in the southeastern Baltic Sea during the past six decades. Bull. Sea Fish. Inst. 2(156): 57-67.

Köster, F.W., Hinrichsen, H., Schnack, D., John, M. a S.T., Mackenzie, B.R., Tomkiewicz, J., Möllmann, C., Kraus, G., Plikshs, M., Makarchouk, A., and Aro, E. 2003. Recruitment of Baltic cod and sprat stocks : identification of critical life stages and incorporation of environmental variability into stock-recruitment relationships. Sci. Mar. 67: 129-154. doi:10.3989/scimar.2003.67s1129.

Krekoukiotis, D., Palacz, A., and John, M.A.S. 2016. Assessing the Role of Environmental Factors on Baltic Cod Recruitment, a Complex Adaptive System Emergent Property. 3: 116. doi:10.3389/fmars.2016.00126.

Kruuk, L.E.B., Osmond, H.L., and Cockburn, A. 2015. Contrasting effects of climate on juvenile body size in a Southern Hemisphere passerine bird. Glob. Chang. Biol. 21(8): 2929-2941. doi:10.1111/gcb.12926.

Kuhn, M. 2008. Building Predictive Models in R Using the caret Package. J. Stat. Softw. 28(5): 1-26. doi:10.1053/j.sodo.2009.03.002.

Kursa, M.B., and Rudnicki, W.R. 2010. Feature Selection with the Boruta Package. J. Stat. Softw. 36(11): 1-13.

Lehmann, A., Krauss, W., and Hinrichsen, H.H. 2002. Effects of remote and local atmospheric forcing on circulation and upwelling in the Baltic Sea. Tellus A 54(3): 299-316. 
669

670

671

672

673

674

675

676

677

678

679

680

681

682

683

684

685

686

687

688

689

690

691

doi:10.1034/j.1600-0870.2002.00289.x.

Liaw, a, and Wiener, M. 2002. Classification and Regression by randomForest. R news 2: 1822. doi:10.1177/154405910408300516.

Lindegren, M., and Checkley, D.M. 2013. Temperature dependence of Pacific sardine (Sardinops sagax) recruitment in the California Current Ecosystem revisited and revised. Can. J. Fish. Aquat. Sci. 252: 245-252.

MacKenzie, B.R., Gislason, H., Möllmann, C., and Köster, F.W. 2007. Impact of 21 st century climate change on the Baltic Sea fish community and fisheries. Glob. Chang. Biol. 13: 1348-1367. doi:10.1111/j.1365-2486.2007.01369.x.

MacKenzie, B.R., Horbowy, J., and Köster, F.W. 2008. Incorporating environmental variability in stock assessment: predicting recruitment, spawner biomass, and landings of sprat (Sprattus sprattus) in the Baltic Sea. Can. J. Fish. Aquat. Sci. 65: 1334-1341. doi:10.1139/F08-051.

MacKenzie, B.R., and Köster, F.W. 2004. Fish Production and Climate: Sprat in the Baltic Sea. Ecology 85(3): 784-794. doi:10.1890/02-0780.

MacKenzie, B.R., Meier, H.E.M., Lindegren, M., Neuenfeldt, S., Eero, M., Blenckner, T., Tomczak, M.T., and Niiranen, S. 2012. Impact of Climate Change on Fish Population Dynamics in the Baltic Sea: A Dynamical Downscaling Investigation. Ambio 41(6): 626636. doi:10.1007/s13280-012-0325-y.

Margonski, P., Hansson, S., Tomczak, M.T., and Grzebielec, R. 2010. Climate influence on Baltic cod, sprat, and herring stock-recruitment relationships. Prog. Oceanogr. 87: 277-288. doi:10.1016/j.pocean.2010.08.003.

Möllmann, C., Diekmann, R., Müller-karulis, B., Kornilovs, G., Plikshs, M., and Axe, P. 2009. 
692

693

694

695

696

697

698

699

700

701

702

703

704

705

706

707

708

709

710

711

712

713

714

Reorganization of a large marine ecosystem due to atmospheric and anthropogenic pressure: A discontinuous regime shift in the Central Baltic Sea. Glob. Chang. Biol. 15: 1377-1393. doi:10.1111/j.1365-2486.2008.01814.x.

Möllmann, C., Kornilovs, G., Fetter, M., Köster, F.W., and Hinrichsen, H.-H. 2003. The marine copepod, Pseudocalanus elongatus, as a mediator between climate variability and fisheries in the Central Baltic Sea. Fish. Oceanogr. 12: 360-368. doi:10.1046/j.13652419.2003.00257.x.

Olden, J.D., Lawler, J.J., and Poff, N.L. 2008. Machine learning methods without tears: a primer for ecologists. Q. Rev. Biol. 83(2): 171-193. doi:10.1086/587826.

Podolska, M., Horbowy A N, J., and Wyszyński, D.M. 2006. Discrimination of Baltic herring populations with respect to Anisakis simplex larvae infection. J. Fish Biol. 68: 1241-1256. doi:10.1111/j.1095-8649.2006.01004.x.

van de Pol, M., Bailey, L.D., McLean, N., Rijsdijk, L., Lawson, C.R., Brouwer, L., and Gimenez, O. 2016. Identifying the best climatic predictors in ecology and evolution. Methods Ecol. Evol. 7(10): 1246-1257. doi:10.1111/2041-210X.12590.

Prasad, A.M., Iverson, L.R., and Liaw, A. 2006. Newer classification and regression tree techniques: Bagging and random forests for ecological prediction. Ecosystems 9(2): 181199. doi:10.1007/s10021-005-0054-1.

R Development Core Team. 2011. R: A language and environment for statistical computing. R Foundation for Statistical Computing, Vienna, Austria. Available from http://www.rproject.org.

Raid, T., Kornilovs, G., Lankov, A., Nisumaa, A.M., Shpilev, H., and Järvik, A. 2010. Recruitment dynamics of the Gulf of Riga herring stock: Density-dependent and 
715

716

717

718

719

720

721

722

723

724

725

726

727

728

729

730

731

732

733

734

735

736

737

environmental effects. ICES J. Mar. Sci. 67: 1914-1920. doi:10.1093/icesjms/fsq128.

Rajasilta, M. 1993. Spawning of herring (Clupea harengus membras L.) in the Archipelago Sea. ICES J. Mar. Sci. 50: 233-246. doi:10.1006/jmsc.1993.1026.

Shepherd, J.G. 1997. Prediction of year-class strength by calibration regression analysis of multiple recruit index series. ICES J. Mar. Sci. 54(5): 741-752. doi:10.1006/jmsc.1997.0222.

Smoliński, S., and Radtke, K. 2017. Spatial prediction of demersal fish diversity in the Baltic Sea: comparison of machine learning and regression-based techniques. ICES J. Mar. Sci. 74(1): 102-111. doi:10.1093/icesjms/fsw136.

Stekhoven, D.J., and Bühlmann, P. 2012. Missforest-Non-parametric missing value imputation for mixed-type data. Bioinformatics 28(1): 112-118. doi:10.1093/bioinformatics/btr597.

Subbey, S., Devine, J.A., Schaarschmidt, U., and Nash, R.D.M. 2014. Modelling and forecasting stock-recruitment: current and future perspectives. ICES J. Mar. Sci. 71: 2307-2322.

Teller, B.J., Adler, P.B., Edwards, C.B., Hooker, G., and Ellner, S.P. 2016. Linking demography with drivers: Climate and competition. Methods Ecol. Evol. 7(2): 171-183. doi:10.1111/2041-210X.12486.

Touw, W.G., Bayjanov, J.R., Overmars, L., Backus, L., Boekhorst, J., Wels, M., and Sacha van Hijum, A.F.T. 2013. Data mining in the life sciences with random forest: A walk in the park or lost in the jungle? Brief. Bioinform. 14(3): 315-326. doi:10.1093/bib/bbs034.

Voss, R., Peck, M.A., Hinrichsen, H.H., Clemmesen, C., Baumann, H., Stepputtis, D., Bernreuther, M., Schmidt, J.O., Temming, A., and Köster, F.W. 2012. Recruitment processes in Baltic sprat - A re-evaluation of GLOBEC Germany hypotheses. Prog. Oceanogr. 107: 61-79. doi:10.1016/j.pocean.2012.05.003. 
738 Wright, M.N., and Ziegler, A. 2015. ranger: A Fast Implementation of Random Forests for High 739 Dimensional Data in C++ and R. Available from http://arxiv.org/abs/1508.04409. 
Table 1. List of variables used in the modeling of Baltic herring and sprat recruitment.

\begin{tabular}{lll}
\hline $\begin{array}{l}\text { Variable } \\
\text { abbreviations }\end{array}$ & Description & Source \\
\hline $\begin{array}{l}\text { Biological data } \\
\text { her/sprR }\end{array}$ & Herring or sprat recruitment at age 1 & \\
her/sprSSB & Herring or sprat spawning stock biomass & (ICES 2016) \\
her/sprWAAx & Herring or sprat weight at age x & (ICES 2016) \\
codTSB & Total stock biomass of cod in subdivisions 25-32 & (ICES 2013) \\
Hydroclimatic data & & \\
SST & Mean sea surface temperature & (Huang et al. 2015) \\
BSI & Mean Baltic Sea Index & (Lehmann et al.
\end{tabular}


Table 2. Optimal time windows for the hydroclimatic signals revealed during two iterations of the RF "sliding window" analysis. Windows are defined as the month before the reference date (end of spawning year), and calendar months are given with the year lag in brackets.

Window open Window close

\begin{tabular}{lll}
\hline Herring & & \\
$\mathrm{BSI}-1^{\text {st }}$ step & 24 (December-2 y) & 14 (October-1 y) \\
$\mathrm{BSI}-2^{\text {nd }}$ step & 16 (August-1 y) & 0 (December) \\
$\mathrm{SST}-1^{\text {st }}$ step & 9 (March) & 5 (July) \\
$\mathrm{SST}-2^{\text {nd }}$ step & 22 (February-1 y) & 21 (March-1 y) \\
$\mathrm{Sprat}$ & & \\
$\mathrm{BSI}-1^{\text {st }}$ step & 11 (January) & 9 (March) \\
$\mathrm{BSI}-2^{\text {nd }}$ step & 19 (May-1 y) & 19 (May-1 y) \\
$\mathrm{SST}-1^{\text {st }}$ step & 4 (August) & 3 (September) \\
$\mathrm{SST}-2^{\text {nd }}$ step & 32 (April-2 y) & 23 (January-1 y)
\end{tabular}


Table 3. Results of the cross-validation of the random forest and Ricker recruitment models that incorporate different sets of predictors. Prediction accuracy (median, 25 $5^{\text {th }}$ and $75^{\text {th }}$ percentile of $\mathrm{R}^{2}$ metric distribution) of the models are given.

\begin{tabular}{lccccccc} 
& \multicolumn{3}{c}{ Herring } & \multicolumn{3}{c}{ Sprat } \\
\hline & \multicolumn{3}{c}{ Percentile } & \multicolumn{3}{c}{ Percentile } \\
Model: variables included & $25^{\text {th }}$ & median & $75^{\text {th }}$ & $25^{\text {th }}$ & median & $75^{\text {th }}$ \\
\hline $\begin{array}{l}\text { Random Forest: all relevant variables } \\
\text { Random Forest: SSB + hydroclimatic }\end{array}$ & 0.464 & 0.646 & 0.744 & 0.321 & 0.513 & 0.676 \\
variables & & & & & & \\
Random Forest: biological variables & 0.224 & 0.384 & 0.558 & 0.463 & 0.618 & 0.762 \\
Random Forest: SSB & 0.259 & 0.451 & 0.634 & 0.028 & 0.097 & 0.294 \\
Ricker: SSB + hydroclimatic variables & 0.015 & 0.061 & 0.167 & 0.015 & 0.070 & 0.210 \\
Ricker: SSB & 0.409 & 0.421 & 0.429 & 0.262 & 0.282 & 0.300 \\
a - based on preliminary AIC comparisons only first SST and first BSI signals were included & \\
in the modified Ricker models. & & & & & & &
\end{tabular}




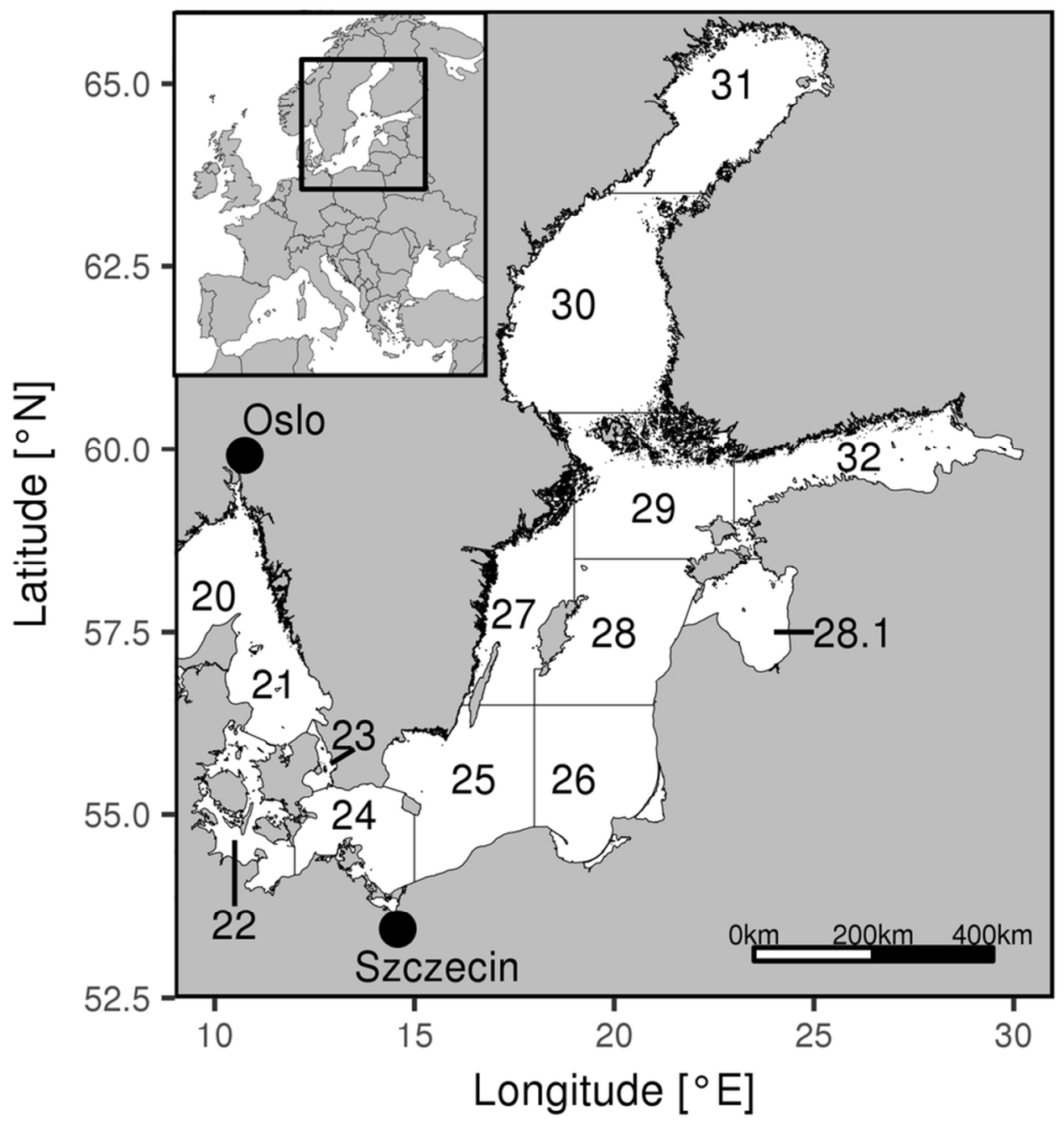

Fig. 1. Map of the Baltic Sea with the indicated subdivisions of the International Council for the Exploration of the Sea (ICES). Stocks investigated in this study are i) herring in subdivisions 25-29 and 32 (excluding 28.1, i.e., Gulf of Riga) and ii) sprat in subdivisions 22-32. The map was created based on the layer of ICES statistical areas (ICES 2017).

$84 \times 90 \mathrm{~mm}(300 \times 300 \mathrm{DPI})$ 
Creation of the baseline random forest model (including biological data only)

¿

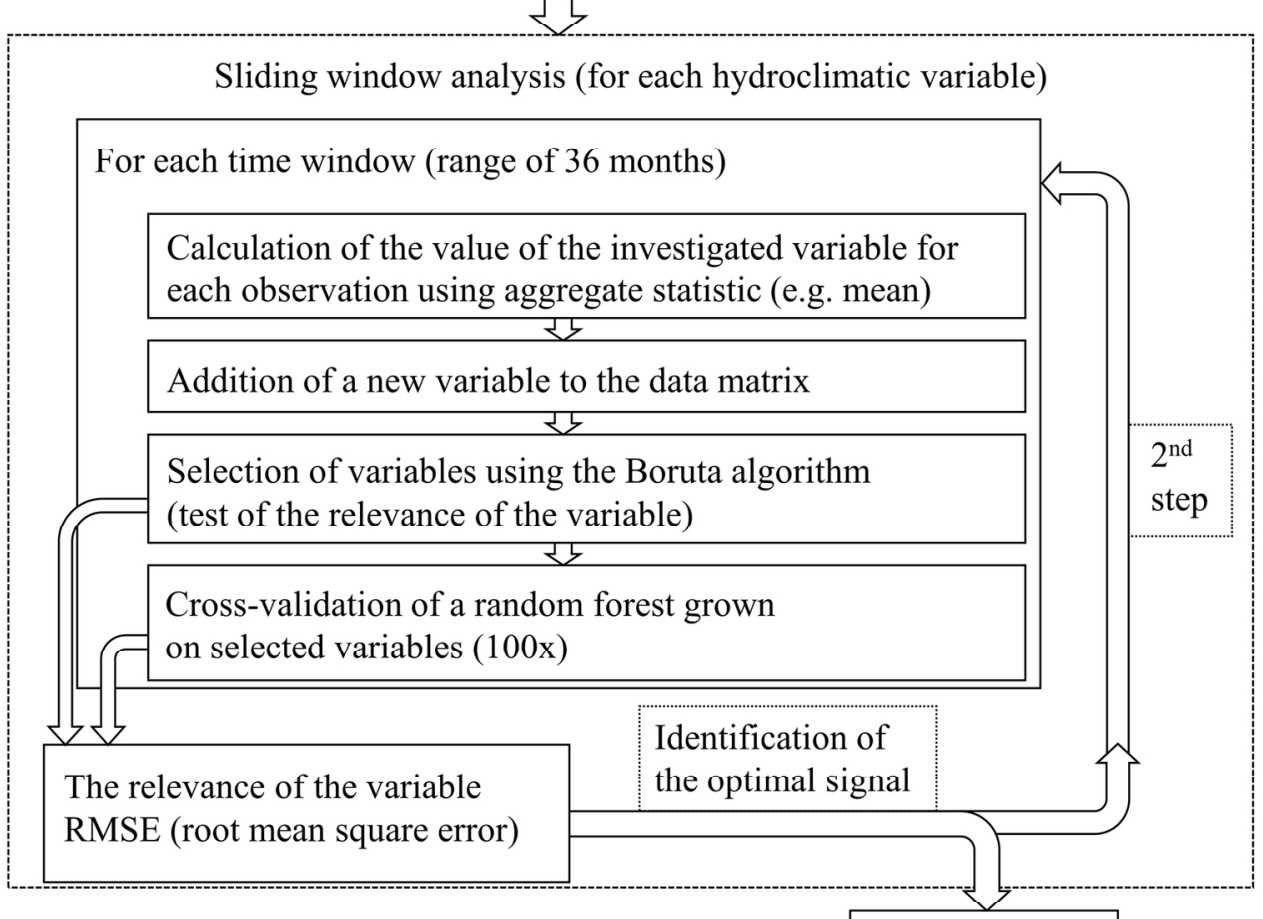

Further analysis

Fig. 2. Flow chart of the analysis conducted separately for herring and sprat data.

$77 \times 67 \mathrm{~mm}(600 \times 600 \mathrm{DPI})$ 


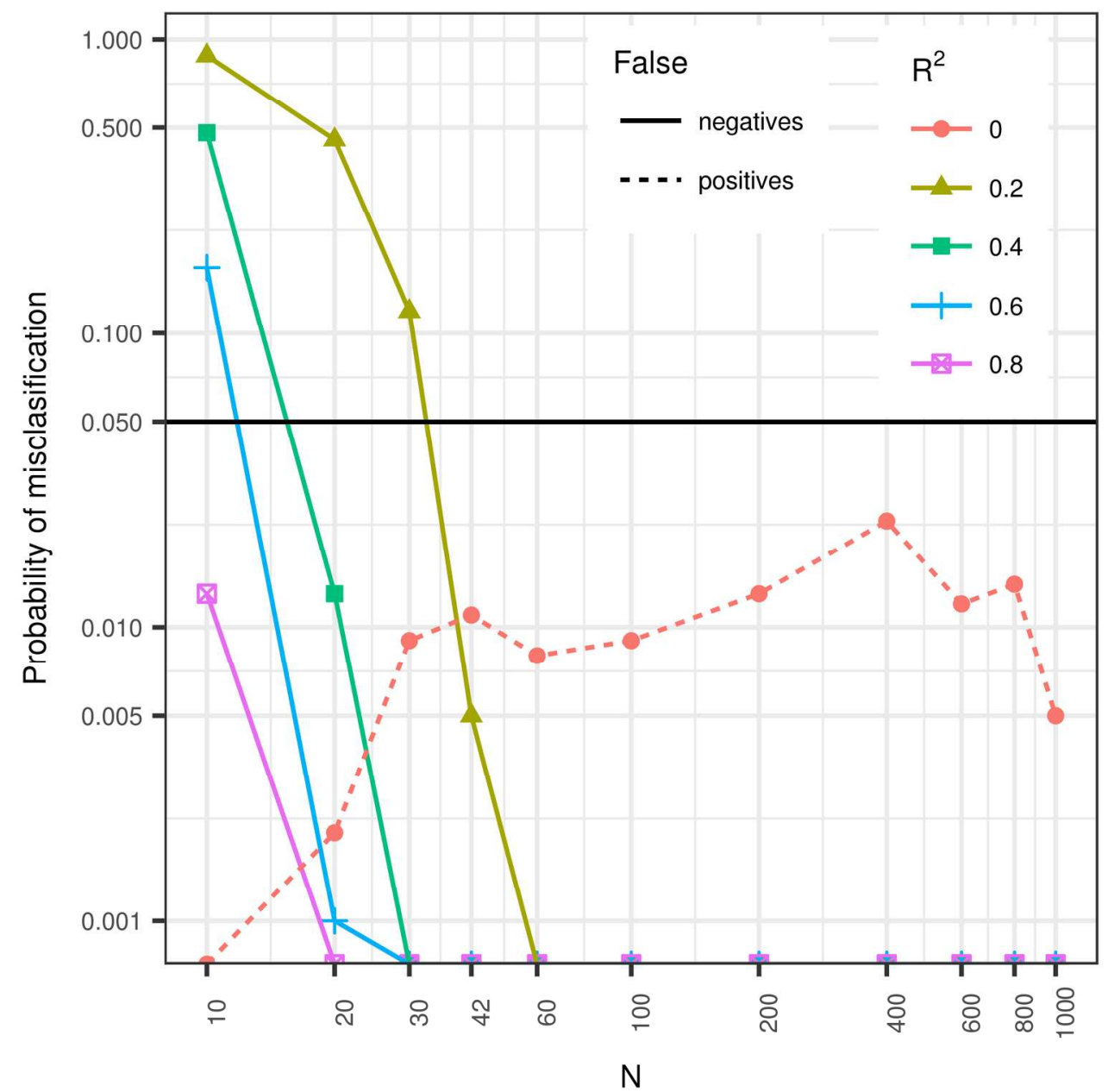

Fig. 3. Probability of misclassification of environmental signal calculated based on the 1000 generated datasets containing response and explanatory (environmental) variables with known correlation between them (colors). Different sample sizes (x-axis) were considered in the simulation. Level of 0.05 was indicated with the solid line. Log-scale was used on the $x$ and $y$-axis. Data points at the lower bound of the plot indicate the zero misclassification rate.

$89 \times 89 \mathrm{~mm}(600 \times 600$ DPI $)$ 

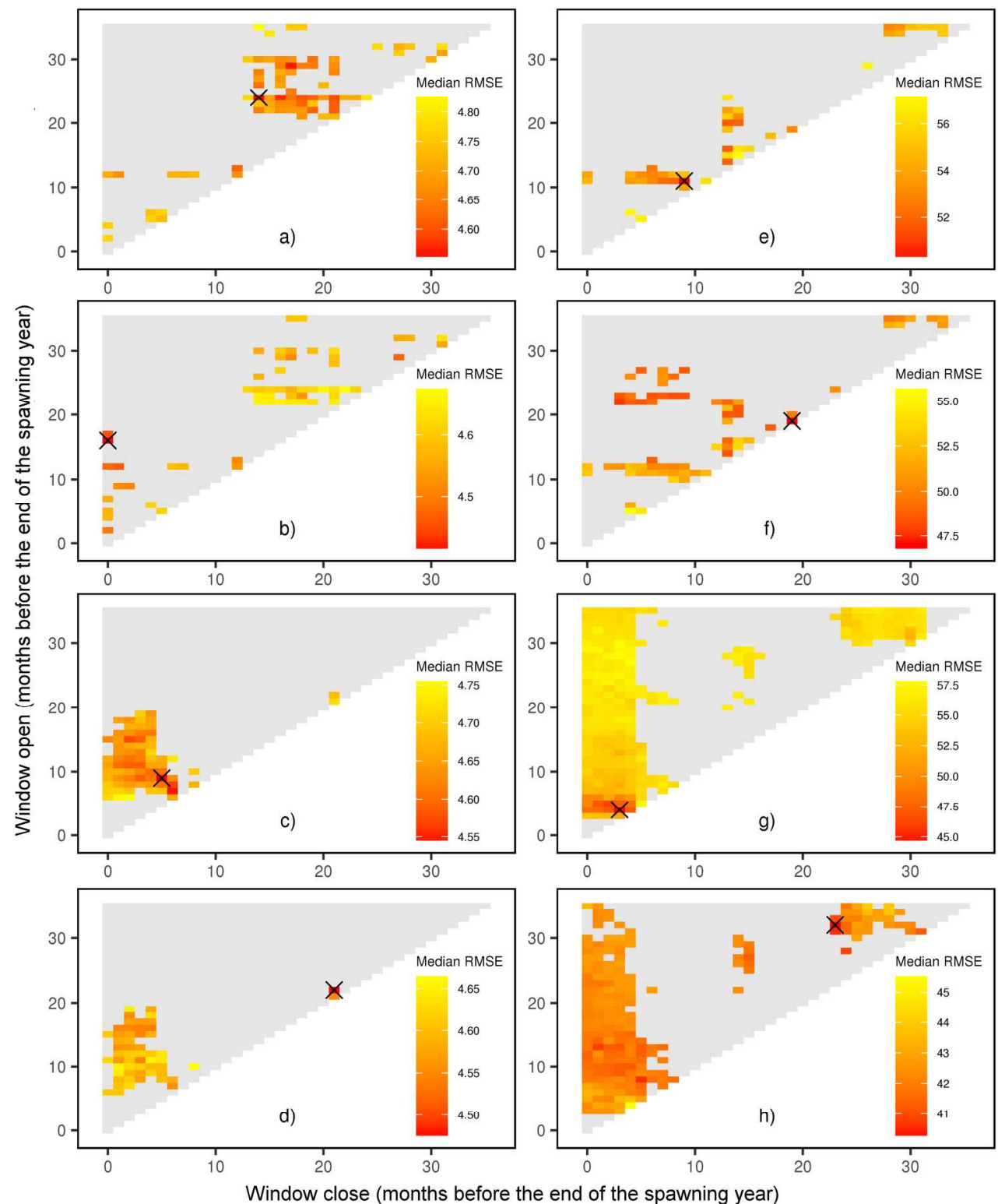

Fig. 4. Results of the random forest "sliding window" analysis for the environmental effects on herring (a-d) and sprat (e-h) recruitment. Outcomes of the first $(a, e, c, g)$ and second $(b, f, d, h)$ steps of the optimal signal identification process for the BSI $(a, b, e, f)$ and SST $(c, d, g, h)$ are shown on the plots. The root mean squared errors (RMSEs) of random forest models for each time window are visualized with a color gradient. Only the RMSEs of models in which hydroclimatic factors were relevant (according to Boruta tests) are colored. The best-supported time window is marked with an $\mathrm{x}$. 

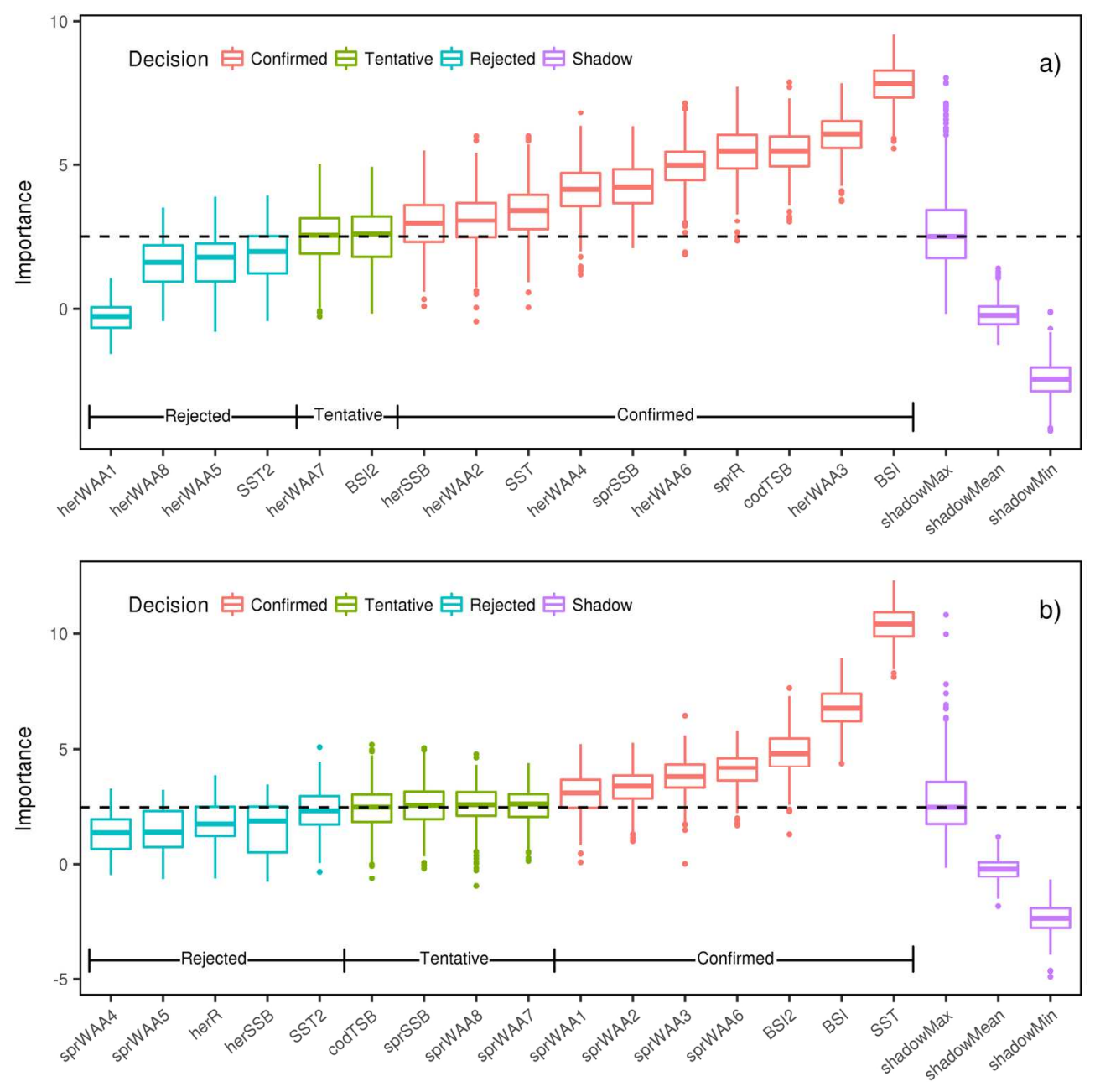

Fig. 5. Results of the Boruta tests of the relevance of predictors in the random forest model of herring (a) and sprat (b) recruitment. The distribution of importance estimates of variables obtained during Boruta runs are shown with boxplots. The median of the highest importance of the shadow attribute (shadowMax), which constitutes the reference level for the decision, is marked with a dashed line. Distributions of minimal and

mean Z-scores of shadow attributes (shadowMin and shadowMean, respectively) provide additional information about the stochasticity of the information system. Boruta decisions on tested predictors are indicated with colors of boxplots.

$164 \times 164 \mathrm{~mm}(300 \times 300 \mathrm{DPI})$ 

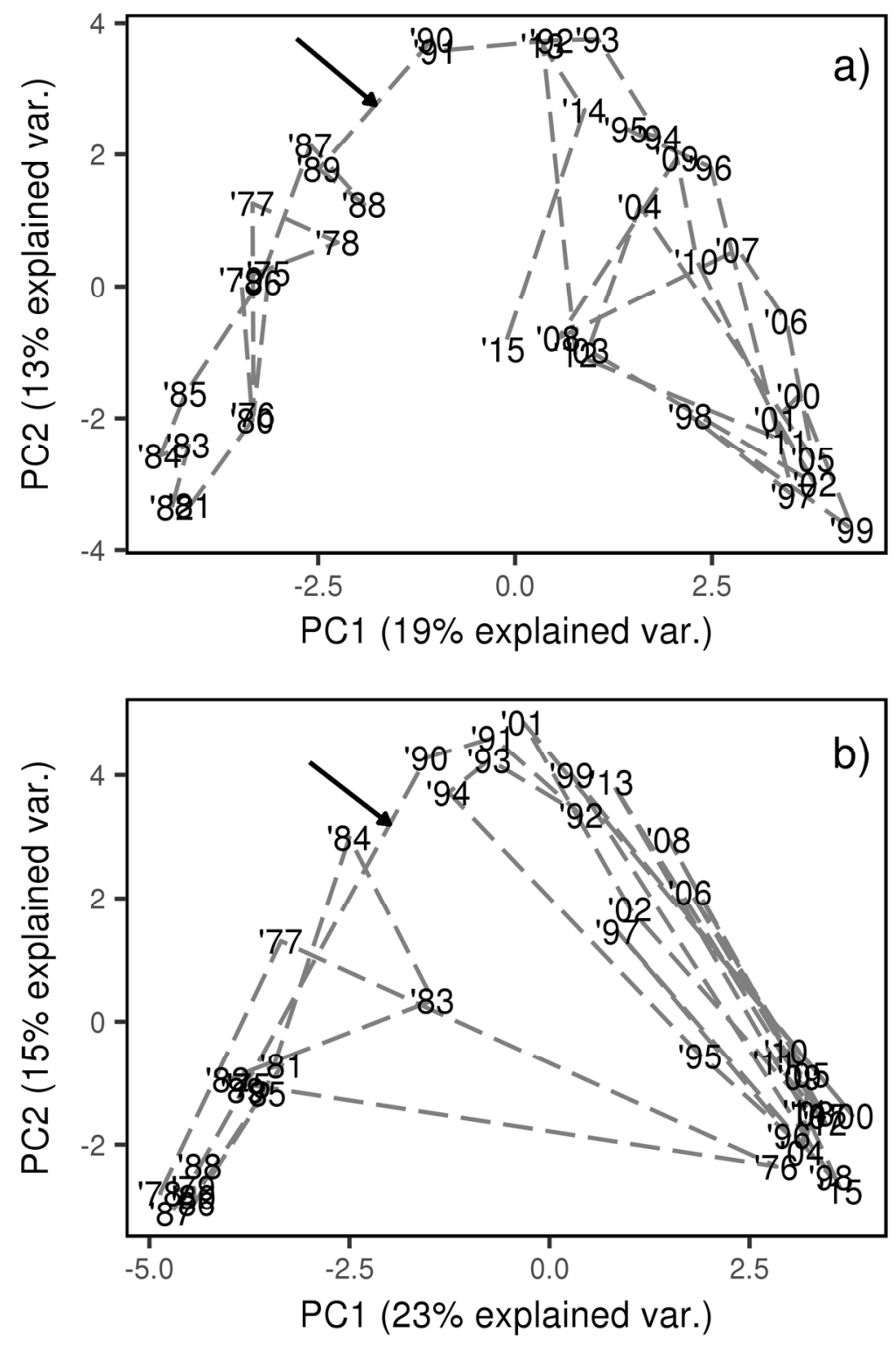

Fig. 6. Plot of the first two principal component scores derived by the PCA based on a proximity matrix of the recruitment years of herring (a) and sprat (b). Times of major alterations in recruitment are indicated with arrows.

$119 \times 180 \mathrm{~mm}(300 \times 300$ DPI) 
a)
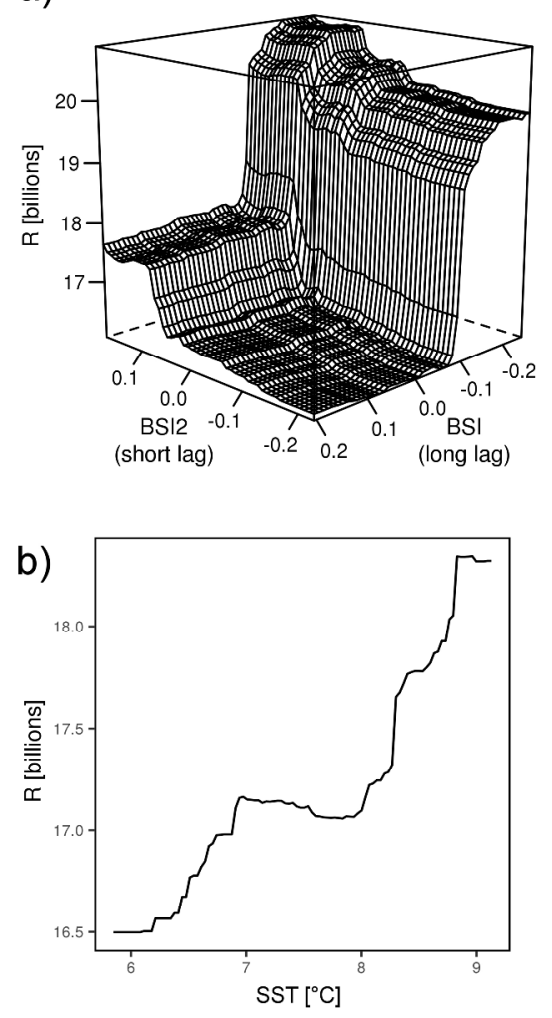

c)

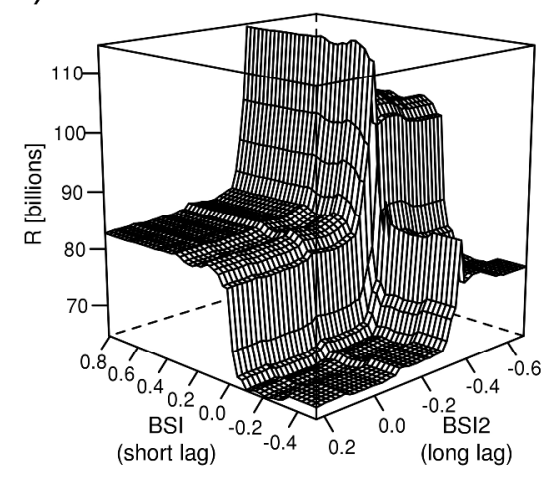

d)

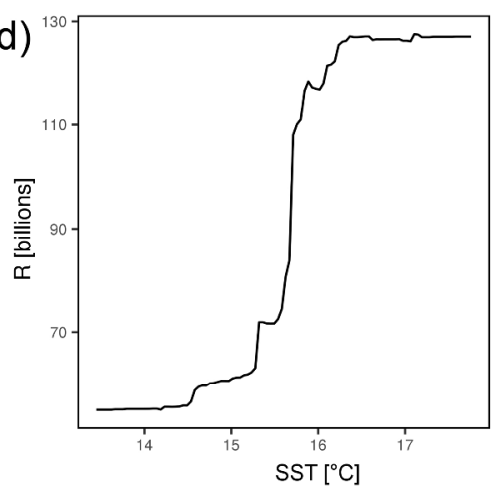

Fig. 7. Partial dependence plots for the hydroclimatic variables for random forest predictions of herring $(a, b)$ and sprat (c, d) recruitment. The effects of different BSI signals (according to results of the 1st and 2nd steps of the "sliding window" analysis; see Table 2) are presented.

$$
329 \times 277 \mathrm{~mm} \text { ( } 300 \times 300 \text { DPI) }
$$



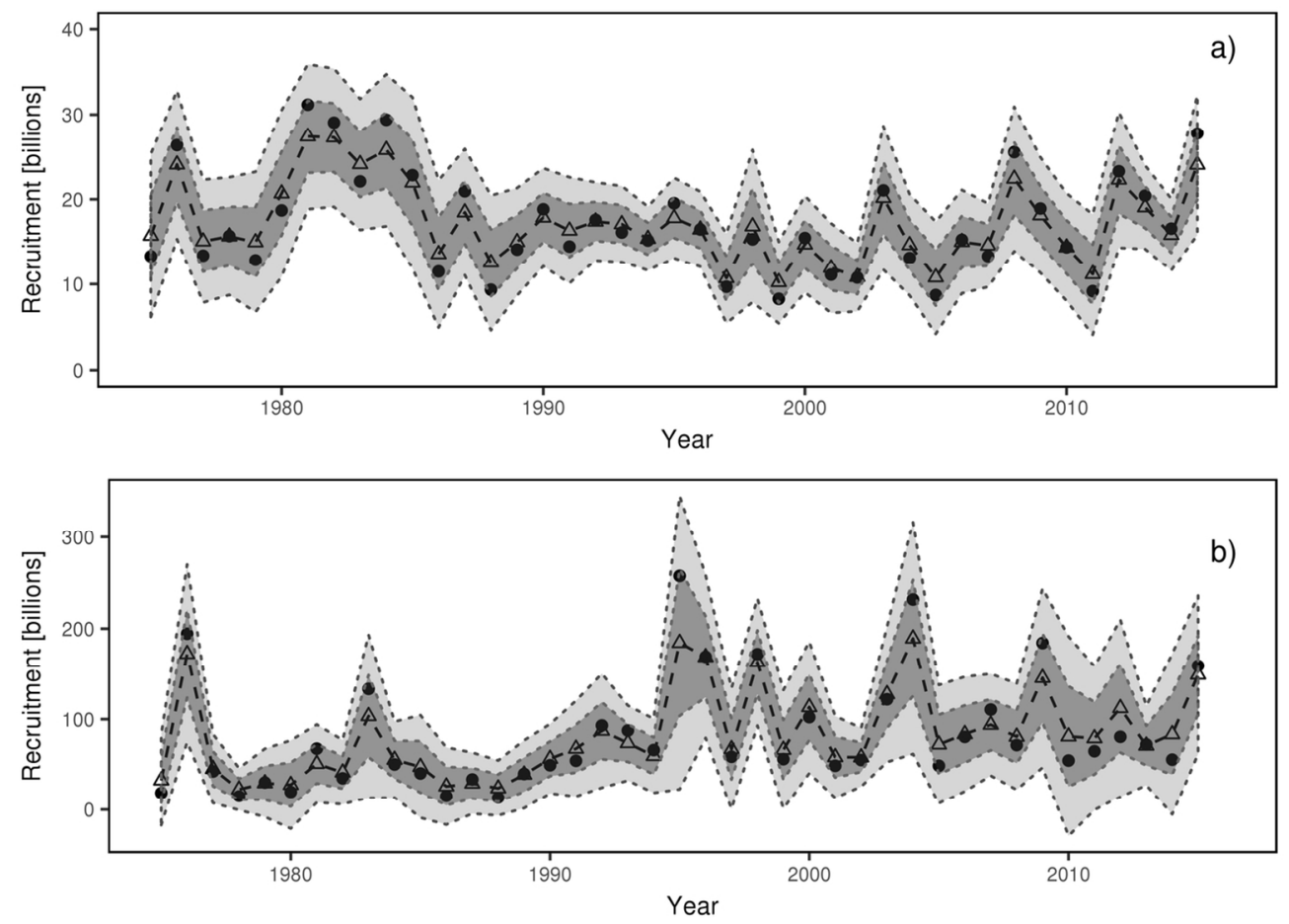

Fig. 8. Plot of the observed (points) recruitment and predicted recruitment by the random forest model (open triangles) of herring (a) and sprat (b). Prediction uncertainty ( \pm 1 or 2 standard deviations of all individual predictions in the ensemble) is represented with shaded areas.

$119 \times 87 \mathrm{~mm}(300 \times 300 \mathrm{DPI})$ 